\title{
Mycophenolate mofetil versus cyclosporine for remission maintenance in nephrotic syndrome
}

\author{
Eiske M. Dorresteijn • Joana E. Kist-van Holthe • \\ Elena N. Levtchenko • Jeroen Nauta • Wim C. J. Hop • \\ Albert J. van der Heijden
}

Received: 19 December 2007 / Revised: 20 May 2008 / Accepted: 20 May 2008 / Published online: 12 July 2008

(C) The Author(s) 2008

\begin{abstract}
We performed a multi-centre randomized controlled trial to compare the efficacy of mycophenolate mofetil (MMF) to that of cyclosporine A (CsA) in treating children with frequently relapsing nephrotic syndrome and biopsy-proven minimal change disease. Of the 31 randomized initially selected patients, seven were excluded. The remaining 24 children received either MMF $1200 \mathrm{mg} / \mathrm{m}^{2}$ per day $(n=12)$ or CsA $4-5 \mathrm{mg} / \mathrm{kg}$ per day $(n=12)$ during a 12 -month period. Of the 12 patients in the MMF group, two discontinued the study medication. Evaluation of the changes from the baseline glomerular filtration rate showed an overall significant difference in favour of MMF over the treatment period $(p=0.03)$. Seven of the 12 patients in the MMF group and 11 of the 12 patients in the CsA group remained in complete remission during the entire study period. Relapse rate in the MMF group was $0.83 /$ year compared to $0.08 /$ year in the CsA group $(p=0.08)$. None of
\end{abstract}

\author{
E. M. Dorresteijn $(\bowtie) \cdot J$. Nauta $\cdot$ A. J. van der Heijden \\ Department of Pediatric Nephrology, \\ Erasmus Medical Center/Sophia Children's Hospital, \\ Dr Molewaterplein 60, \\ 3015 GJ Rotterdam, the Netherlands \\ e-mail: e.dorresteijn@erasmusmc.nl \\ J. E. Kist-van Holthe \\ Department of Pediatric Nephrology, \\ Leiden University Medical Center, \\ Leiden, the Netherlands \\ E. N. Levtchenko \\ Department of Pediatric Nephrology, \\ University Hospital Leuven, \\ Leuven, Belgium \\ W. C. J. Hop \\ Department of Epidemiology and Biostatistics, \\ Erasmus Medical Center Rotterdam, \\ Rotterdam, the Netherlands
}

the patients reported diarrhea. Pharmacokinetic profiles of mycophenolic acid were performed in seven patients. The patient with the lowest area under the curve had three relapses within 6 months. In children with frequently relapsing minimal change nephrotic syndrome, MMF has a favourable side effect profile compared to CsA; however, there is a tendency towards a higher relapse risk in patients treated with MMF.

Keywords Child - Cyclosporine · Frequent relapsing · Mycophenolate mofetil $\cdot$ Nephrotic syndrome

\section{Introduction}

Nephrotic syndrome in children is primarily $(77 \%)$ caused by minimal change disease [1]. The vast majority $(92 \%)$ of these patients will respond well to corticosteroids. However, as many as $70 \%$ of children with nephrotic syndrome experience at least one relapse, and 30\% will develop a more complicated course with frequent relapses $(\geq 2$ relapses/ 6 months) with or without steroid dependency (relapse during tapering or within 2 weeks after discontinuation of corticosteroids) [2, 3]. A short course of cyclophosphamide (2-3 months $2-3 \mathrm{mg} / \mathrm{kg}$ per day) will lead to prolonged remission in $25-60 \%$ of children with frequently relapsing nephrotic syndrome $[4,5]$. Most patients $(80 \%)$ who do not respond to cyclophosphamide can achieve prolonged remission with cyclosporine A (CsA), but long-term treatment can have harmful side-effects of which nephrotoxicity and hypertension are the most critical [6-11].

The results from several uncontrolled studies have recently suggested a positive effect of the relatively new immunosuppressive drug mycophenolate mofetil (MMF) in preventing relapses in children with frequently relapsing 
nephrotic syndrome due to minimal changes and various other nephropathies [12-21]. Mycophenolate mofetil inhibits inosine monophosphate dehydrogenase, an enzyme required for the de novo pathway of purine synthesis which, in turn, is essential for the proliferation of $\mathrm{B}$ and $\mathrm{T}$ lymphocytes. In contrast with CsA, MMF has no known nephrotoxic side effects. To the best of our knowledge, there are currently no randomized controlled studies comparing the efficacy of MMF and CsA in treating nephrotic syndrome in children or adults. Furthermore, pharmacokinetic profiles of MMF in children are scarce and mainly concern renal transplant recipients using multiple drugs [22, 23].

We performed a randomized controlled trial to study the efficacy and side effects of MMF compared to CsA in children with frequently relapsing nephrotic syndrome and biopsy proven minimal change disease.

\section{Methods}

General outline of the study

This was a multi-centre randomized controlled trial aimed at studying the efficacy and side effects of MMF compared to CsA in children with frequently relapsing nephrotic syndrome. We also performed a pharmacokinetic study of MMF. Patients were enrolled between January 2003 and June 2005 in six University Hospitals in the Netherlands and Belgium. The ethics committees of the hospitals approved the study protocol. Informed consent was obtained after written and oral information was given.

\section{Inclusion and exclusion criteria}

Children $(<18$ years $)$ with frequently relapsing nephrotic syndrome with or without steroid dependency, despite cyclophosphamide therapy, were asked to participate in the study. Inclusion requirements were glomerular filtration rate $(\mathrm{GFR})>80 \mathrm{ml} / \mathrm{min}$ per $1.73 \mathrm{~m}^{2}$ and biopsy-proven minimal change disease. Patients already on CsA medication were still eligible for the study. The children had to be in remission at study entry (trace or nil proteinuria, as determined by the dipstick test or $<100 \mathrm{mg} / \mathrm{dl}$ for at least 3 days). Patients with severe leucopenia (leucocytes $<3.0 \times$ 1000 cells $/ \mathrm{mm}^{3}$ ), severe anemia (haemoglobin $<8.9 \mathrm{~g} / \mathrm{dl}$ ) or active infection were excluded from the study.

Study medication

Group A patients were treated for 12 months with MMF, $1200 \mathrm{mg} / \mathrm{m}^{2}$ per day b.i.d. (two doses per day, maximum dose $1 \mathrm{~g}$ twice daily). In the case of severe leucopenia, severe anemia, diarrhea (see Follow-up) or serious infection, the dose was decreased by $25 \%$. If side effects persisted, the dose was reduced by an additional $25 \%$ of the initial dose. Dose adjustment was not based on mycophenolate trough levels.

Group B patients were treated for 12 months with the conventional treatment, which consists of CsA $4-5 \mathrm{mg} / \mathrm{kg}$ per day b.i.d. The dose was adjusted aiming at trough levels of $50-150 \mu \mathrm{g} / \mathrm{l}$. In total, four different assays were used [six patients, EMIT (enzyme multiplied immunoassay technique); three, FPIA (fluorescence polarization immunoassay); two, ACMIA (antibody conjugated magnetic immunoassay); one, AxSYM (human chorionic gonadotropin test)]; however, all participating centres standardly aim at a trough level of 50 $150 \mu \mathrm{g} / \mathrm{l}$ for their nephrotic patients irrespective of the method used. In patients already on CsA medication at study entry, the CsA was tapered and stopped within 2 weeks after starting MMF therapy (group A) or continued (group B).

Nephrotic syndrome relapses, defined as proteinuria of $3+$ or more by the dipstick test or $>40 \mathrm{mg} / \mathrm{m}^{2}$ per hour for more than 3 days after a period of remission, were treated with prednisolone $60 \mathrm{mg} / \mathrm{m}^{2}$ once daily until remission was achieved, followed by 4 weeks of $40 \mathrm{mg} / \mathrm{m}^{2}$ every other day or other tapering regimes at the discretion of the treating pediatrician.

\section{Follow-up}

Every 3 months during the study-period of 12 months, the number of relapses, (gastro-intestinal) side effects and additional medication were noted. Diarrhea was defined as an unusually frequent passage of loose stools that required intervention. The mean dose of prednisolone $(\mathrm{mg} / \mathrm{kg}$ per day) over the 12-month study period was calculated. Blood pressure was also measured, and the patient was checked for gingival hyperplasia and hypertrichosis. An automatic device was used to measure blood pressure, which was then compared to that of healthy children of the same gender, age and height [24]. Hypertension was defined as a systolic and/or diastolic blood pressure $>1.64$ SDS (95th percentile) or when antihypertensive medication was prescribed (excluding indications such as proteinuria or headache).

In addition, blood count, serum creatinine, serum albumen, CsA or MMF trough levels and urine protein/ creatinine were determined. The GFR was calculated using an adapted Schwartz formula [25, 26]. Serum lipids [cholesterol, triglycerides, low-density lipoprotein-cholesterol (LDL) and high-density lipoprotein cholesterol (HDL)] were measured at study entry and after 1 year.

Pharmacokinetic study of mycophenolic acid

Mycophenolic acid (MPA) area under the curve (AUC) was determined after 3-6 months of treatment, while patients were in remission, by the limited sampling method 
according to Schütz [27]. Blood samples were taken predose and 75 and $360 \mathrm{~min}$ after the morning dose. The AUC was calculated using the formula $\mathrm{AUC}=5.2+7.1 \times$ $\mathrm{C}_{0 \text { min }}+1 \times \mathrm{C}_{75 \min }+5.4 \times \mathrm{C}_{360 \text { min }}$. To measure the levels of MPA, we used an immunoassay for ten patients (EMITMPA Assay; Behring Diagnostics, San Jose, CA) and a high-pressure liquid chromatography system with a UV detector (HPLC-UV; Merck-Hitachi, Stuttgart, Germany) for two patients.

\section{Statistics}

Patients were stratified for both recent use of CsA and treatment centre and subsequently randomized, based on a computer-generated randomization list, using opaque sealed envelopes prepared by the trial statistician. Study-patients and investigators were not blinded to treatment group. Patients who did not complete the 12-month study period were included in the analysis according to the intention-totreat-principle.

The primary end point in this study was GFR. Secondary end points were relapse-free survival time, occurrence of diarrhea, blood pressure and blood count parameters. Assuming a standard deviation for GFR of $20 \mathrm{ml} / \mathrm{min}$ per $1.73 \mathrm{~m}^{2}$, we calculated that 20 patients in each group was sufficient to detect a difference in GFR of $18 \mathrm{ml} / \mathrm{min}$ per $1.73 \mathrm{~m}^{2}$ between both groups $(p<0.05$, power $=80 \%)$. We had aimed at 20 patients in each group, but failed to enrol these, among other reasons due to the growing preference of MMF treatment in this group of patients.

Differences between the groups at baseline were tested with the Mann-Whitney $U$ test for continuous data and the chi-square test for categorical data. Kaplan-Meier curves were used to compare relapse-free survival time between the two groups. Relapse rate, prednisolone dose and MPA trough levels were analysed by the Mann-Whitney $U$ test. The longitudinal measurements of GFR, blood pressure and blood count parameters were analyzed using repeated measurements analysis of variance (ANOVA) with baseline values as covariates. The GFR was logarithmically transformed in this analysis to approximate normal distributions. Serum lipids were analysed by ANOVA. A $p$ value $<0.05$ was considered to be significant. All computations were carried out in SPSS ver. 11.5 (SPSS, Chicago, IL).

\section{Results}

Of the 31 randomized patients with frequently relapsing nephrotic syndrome who were originally selected for the study, seven were excluded (Fig. 1). The remaining 24 children were evaluated during the study, and their patient characteristics at baseline are summarized in Table 1. Renal

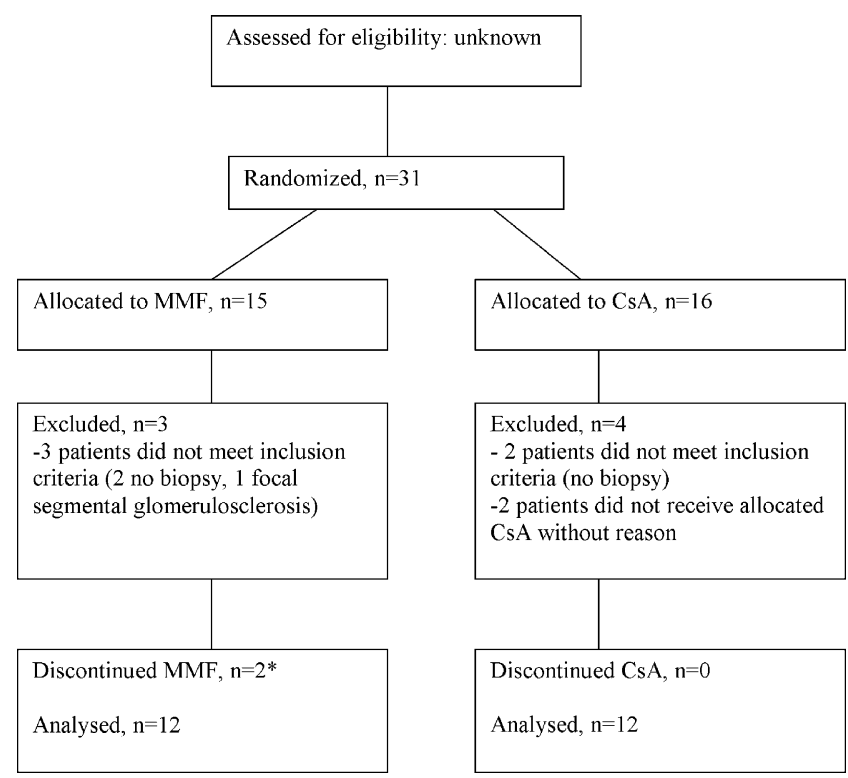

Fig. 1 Flow chart of the study comparing mycophenolate mofetil $(M M F)$ and cyclosporine $(C s A)$ for remission maintenance in nephrotic syndrome. Asterisk indicates frequent relapses. There was one request for withdrawal from the study

biopsy was performed 20 months (median, range 0-110 months) prior to the onset of the study. Cyclophosphamide was given in 23 of the 24 patients at a dosage of $2-3 \mathrm{mg} / \mathrm{kg}$ per day for 8 weeks. The study medication was discontinued during the study-period in two patients receiving MMF (see Efficacy).

\section{Glomerular filtration rate}

Mean estimated GFR in the MMF group increased by $6 \mathrm{ml} / \mathrm{min}$ per $1.73 \mathrm{~m}^{2}$ in 1 year; during the same period, the estimated GFR in the CsA group declined by $14 \mathrm{ml} / \mathrm{min}$ per $1.73 \mathrm{~m}^{2}$ (Table 2). The use of CsA medication prior to randomization did not cause a significant difference in GFR between both groups (mean change in GFR with or without prior CsA medication in the MMF group was $5 \mathrm{ml}$ versus $7 \mathrm{ml} / \mathrm{min}$ per $1.73 \mathrm{~m}^{2}$; in the CsA group, this was $-10 \mathrm{vs}$. $-16 \mathrm{ml} / \mathrm{min}$ per $1.73 \mathrm{~m}^{2}$, respectively). Follow-up values for GFR were on average 13\% lower (95\% confidence interval: $1-23 \%, p=0.03)$ in patients treated with CsA. After 3, 6 and 12 months of drug therapy, the mean GFR of the CsA group was significantly lower than the baseline value ( $p=0.048,0.041,0.013$, respectively); this is in contrast to the MMF group, where no significant changes from baseline were found (Fig. 2). One patient with CsA had slightly impaired renal function (GFR $77 \mathrm{ml} / \mathrm{min}$ per $1.73 \mathrm{~m}^{2}$ ) at the end of the study period, while none of the patients in the MMF group showed any sign of renal impairment. 
Table 1 Patient characteristics and previous treatment for nephrotic syndrome

Data are given as number of patients or as the median, with the range in parenthesis $M M F$ Mycophenolate mofetil; CsA cyclosporine A

\begin{tabular}{llll}
\hline Patient characteristics & MMF & CsA & $p$ \\
\hline Number of patients & 12 & 12 & \\
Male & 10 & 11 & 1.00 \\
Age (years) & $10.9(4.0-15.2)$ & $9.2(3.7-17.5)$ & 0.81 \\
Duration of nephrotic syndrome (years) & $5.3(1.1-11.4)$ & $5.2(1.1-12.3)$ & 0.99 \\
Steroid dependency & 8 & 8 & 1.00 \\
Previous treatment & 12 & & 1.00 \\
$\quad$ Cyclophosphamide & $22(5-103)$ & $47(5-153)$ & 0.65 \\
$\quad$ Months before study entry & 0 & 1 & 1.00 \\
$\quad$ Levamisole & 5 & 6 & 0.51 \\
$\quad$ CsA & $2.2(1.4-3.2)$ & $4.0(1-10)$ & \\
$\quad$ Duration of CsA medication (years) & & & \\
\hline
\end{tabular}

\section{Efficacy}

The relapse-free survival curve is shown in Fig. 3. An overview of the number of relapses during the study-period is given in Table 3. Although the relapse rate in the MMF group (0.83/year $\pm 1.27 \mathrm{SD})$ appears to be higher than that in the CsA group (0.08/year $\pm 0.29 \mathrm{SD})$, the difference did not reach significance $(p=0.08)$. One patient with MMF experienced treatment failure, with three relapses within 6 months, which was reason to switch to CsA. While on
CsA for the remaining 6 months of the study, this patient had one more relapse. Of the two patients in the MMF group with two relapses each, one patient admitted to be non-compliant and switched after 6 months to CsA therapy at his own request because of a loss of appetite and recurrence of eczema; the other patient had two dose reductions (see Side effects). Two of five patients with relapses in the MMF group had previous treatment with CsA, versus three of the seven without relapses. The mean prednisolone dose during the 12-month study period was

Table 2 Results from the clinical and laboratory tests throughout the study

\begin{tabular}{|c|c|c|c|c|c|c|c|}
\hline $\begin{array}{l}\text { Clinical and laboratory } \\
\text { parameters }\end{array}$ & $\begin{array}{l}\text { Therapeutic drug } \\
\text { programme }\end{array}$ & 0 months & 3 months & 6 months & 9 months & 12 months & $p^{\mathrm{a}}$ \\
\hline \multirow[t]{2}{*}{ GFR $\left(\mathrm{ml} / \mathrm{min}\right.$ per $\left.1.73 \mathrm{~m}^{2}\right)$} & MMF & $125(34)$ & $123(33)$ & $126(26)$ & $125(31)$ & $131(40)$ & \multirow[t]{2}{*}{0.03} \\
\hline & CsA & $123(22)$ & $112(26)$ & $107(16)$ & $114(18)$ & $109(16)$ & \\
\hline \multirow[t]{2}{*}{ Systolic blood pressure (SDS) } & MMF & $1.04(0.89)$ & $0.87(0.84)$ & $0.61(0.83)$ & $0.89(0.68)$ & $0.62(0.71)$ & \multirow[t]{2}{*}{0.17} \\
\hline & CsA & $1.35(0.93)$ & $1.19(0.56)$ & $1.13(0.78)$ & $1.17(1.05)$ & $0.88(1.16)$ & \\
\hline \multirow[t]{2}{*}{ Diastolic blood pressure (SDS) } & MMF & $0.36(0.77)$ & $0.44(0.80)$ & $0.22(0.63)$ & $0.27(0.71)$ & $0.05(0.68)$ & \multirow[t]{2}{*}{0.57} \\
\hline & CsA & $0.21(0.83)$ & $-0.05(0.77)$ & $0.00(0.72)$ & $0.12(0.89)$ & $0.30(0.91)$ & \\
\hline \multirow[t]{2}{*}{ Haemoglobin (g/dl) } & MMF & $13.5(1.1)$ & $13.2(1.0)$ & $13.0(1.4)$ & $13.0(1.0)$ & $13.5(1.1)$ & \multirow[t]{2}{*}{0.005} \\
\hline & CsA & $13.0(1.3)$ & $12.2(0.6)$ & $12.0(0.3)$ & $11.9(0.8)$ & $12.0(1.0)$ & \\
\hline \multirow[t]{2}{*}{ Leucocytes $\left(\times 1000\right.$ cells $\left./ \mathrm{mm}^{3}\right)$} & MMF & $7.3(2.6)$ & $6.7(1.9)$ & $7.4(3.9)$ & $6.5(2.1)$ & $6.1(1.7)$ & \multirow[t]{2}{*}{0.43} \\
\hline & CsA & $8.1(2.8)$ & $7.0(1.7)$ & $7.7(2.2)$ & $7.7(2.6)$ & $8.1(3.0)$ & \\
\hline \multirow[t]{2}{*}{ Lymphocytes $\left(\times 1000\right.$ cells $\left./ \mathrm{mm}^{3}\right)$} & MMF & $2.5(1.3)$ & $2.5(0.9)$ & $2.0(0.9)$ & $2.0(0.9)$ & $2.0(0.7)$ & \multirow[t]{2}{*}{0.99} \\
\hline & $\mathrm{CsA}$ & $2.8(1.2)$ & $2.3(0.6)$ & $2.3(0.8)$ & $2.0(0.8)$ & $2.3(0.5)$ & \\
\hline \multirow[t]{2}{*}{ Cholesterol (mg/dl) } & MMF & $196(81)$ & & & & $181(89)$ & \multirow[t]{2}{*}{0.59} \\
\hline & CsA & $181(42)$ & & & & $177(31)$ & \\
\hline \multirow[t]{2}{*}{ Triglycerides (mg/dl) } & MMF & $114(50)$ & & & & $84(30)$ & \multirow[t]{2}{*}{0.59} \\
\hline & CsA & $114(50)$ & & & & $85(40)$ & \\
\hline \multirow[t]{2}{*}{ LDL-cholesterol (mg/dl) } & MMF & $104(23)$ & & & & $85(19)$ & \multirow[t]{2}{*}{0.10} \\
\hline & CsA & $112(46)$ & & & & $116(35)$ & \\
\hline \multirow[t]{2}{*}{ HDL-cholesterol (mg/dl) } & MMF & $58(15)$ & & & & $54(8)$ & \multirow[t]{2}{*}{0.60} \\
\hline & CsA & $54(12)$ & & & & $58(12)$ & \\
\hline
\end{tabular}

All values are means, with the standard deviation given in parenthesis

GFR, Glomerular filtration rate; LDL, low-density lipoprotein cholesterol; HDL, high-density lipoprotein cholesterol

${ }^{a}$ The $p$ value compares the overall change from baseline between the two groups 


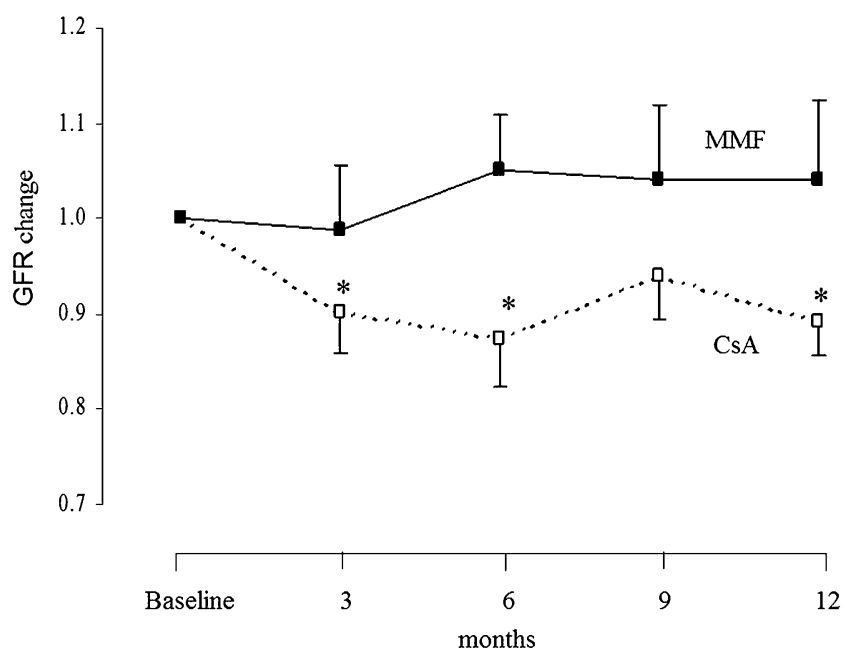

Fig. 2 Change in the glomerular filtration rate $(G F R)$ from baseline for patients receiving mycophenolate mofetil $(M M F, n=12)$ and cyclosporine A (CsA, $n=12)$ medication. The change in the GFR is expressed as ratio compared to baseline. Data are given as ANOVA estimates with standard errors. ${ }^{*} p<0.05$ compared to baseline

not significantly different between the two groups (Table 3). Steroids were only given for the treatment of relapses, with the exception of one patient in the CsA group, who received low dose prednisolone $(5 \mathrm{mg})$ on alternate days as maintenance therapy.

\section{Side effects}

The side effects of MMF drug therapy were generally mild, and most patients tolerated MMF well. The MMF dose of one patient was reduced by $25 \%$ during a bout of pneumonia, and a few months later an additional $25 \%$

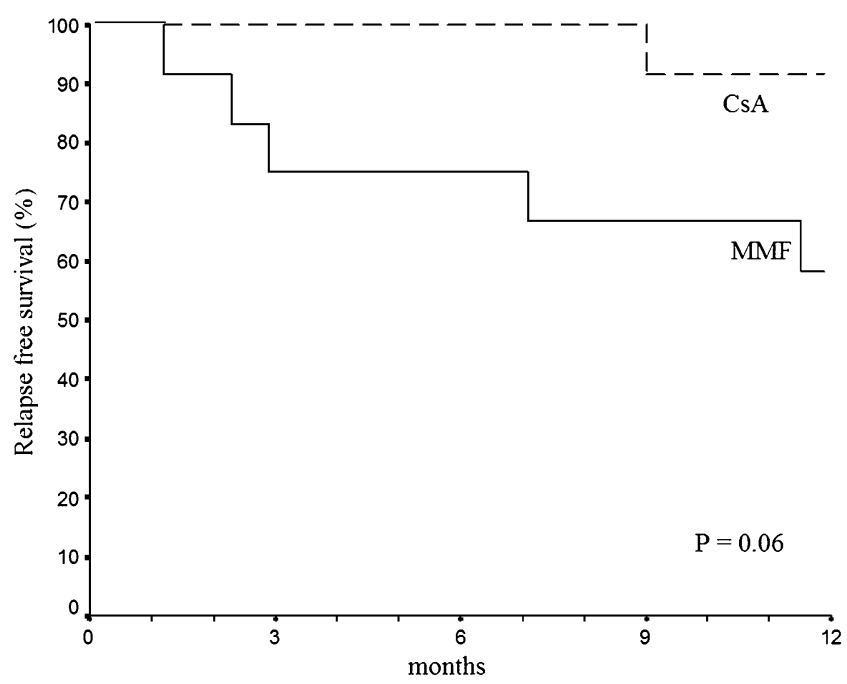

Fig. 3 Relapse-free survival curve for patients with mycophenolate mofetil $(M M F, n=12)$ and cyclosporine A $(C s A, n=12)$ medication. The $p$ value is from the logrank test
Table 3 Efficacy of MMF compared to CsA

\begin{tabular}{llll}
\hline Parameter & MMF & CsA & $p$ \\
\hline Patient $(n)$ & 12 & 12 & \\
CsA $(\mathrm{mg} / \mathrm{kg}$ per day) & - & $5.1(1.1)$ & \\
MMF $\left(\mathrm{mg} / \mathrm{m}^{2}\right.$ per day) & $1173(114)$ & - & \\
Prednisolone $(n)^{\mathrm{a}}$ & 9 & 5 & 0.21 \\
Mean prednisolone dose & $0.13(0.16)$ & $0.08(0.12)$ & 0.21 \\
$\quad(\mathrm{mg} / \mathrm{kg} /$ day) & & & \\
Number of relapses $(n)$ & & & \\
$\quad$ Zero & 7 & 11 & \\
One & 2 & 0 & 0.08 \\
Two & 2 & 0 & \\
$\quad$ Four & 1 & 0.08 & \\
Relapse rate $(n /$ patient & 0.83 & & \\
per year) & &
\end{tabular}

Data are given as mean, with the standard deviation given in parenthesis

${ }^{a}$ Including patients using prednisolone started just before study-entry as relapse treatment

reduction was implemented because of unexplained fatigue; dose modification was not necessary in the other patients. None of the patients experienced diarrhea; however, one patient had a temporary slight increase in defecation frequency (one to three defecations per day), without other gastro-intestinal symptoms or weight loss.

\section{Blood pressure}

Mean blood pressure did not change significantly in both groups during the study period (Table 2). After 12 months, one patient on MMF - compared to four patients on CsAhad hypertension, whereas at baseline four and three patients, respectively, were hypertensive $(p=0.32)$. One patient in the MMF group was treated for hypertension with angiotensin-converting enzyme (ACE) inhibition at study entry; this was withdrawn during the study period. Antihypertensive drugs were not prescribed for any other indications (e.g. proteinuria or headache).

\section{Laboratory parameters}

The laboratory results on the blood count and serum lipids are given in Table 2. At 12 months, the haemoglobin $(\mathrm{Hb})$ level was significantly lower in the CsA group than in the MMF group $(p=0.005)$. None of the patients developed anemia $(\mathrm{Hb}<10.4 \mathrm{mmol} / 1$ in more than one measurement $)$ or leucopenia (leucocytes $<4.0 \times 1000$ cells $/ \mathrm{mm}^{3}$ in more than one measurement). Two patients, one in each group, developed transient mild lymphopenia (lymphocytes 1.00 $1.50 \times 1000$ cells $/ \mathrm{mm}^{3}$ ). Two other patients in the MMF group, both with pre-existing lymphopenia (1.1 and $0.98 \times$ 1000 cells $/ \mathrm{mm}^{3}$, respectively), continued to have low 
lymphocyte counts (minimum $0.95 \times 1000$ cells $/ \mathrm{mm}^{3}$ ) without infections.

\section{Hypertrichosis and gingival hyperplasia}

After 12 months, hypertrichosis occurred in three of eight patients on CsA drug therapy; in contrast none of the patients on MMF medication developed hypertrichosis. Gingival hyperplasia was observed in six of ten patients in the CsA group versus none in the MMF group.

\section{Pharmacokinetic study}

Pharmacokinetic profiles of MPA were determined in seven patients (Fig. 4). During AUC determination, all patients were in remission and using $1098-1315 \mathrm{mg} / \mathrm{m}^{2}$ per day MMF. One patient received co-medication with benazepril and cetirizine, and another patient received prednisolone, calcium and vitamin $\mathrm{D}$; all other patients received MMF monotherapy. The patient with the lowest AUC had three relapses within 6 months while using MMF $1315 \mathrm{mg} / \mathrm{m}^{2}$ per day and showed no evidence of non-compliance

For ten patients on MPA drug therapy, four with relapses and six without, one or more MPA trough levels were available. Mean MPA trough level of patients with relapses was 3.4 (SD 2.4) mg/l compared to 3.6 (SD 1.0) $\mathrm{mg} / \mathrm{l}$ of patients without relapses $(p=0.48)$.

\section{Discussion}

The current standard treatment of frequently relapsing nephrotic syndrome in children with long-term prednisolone

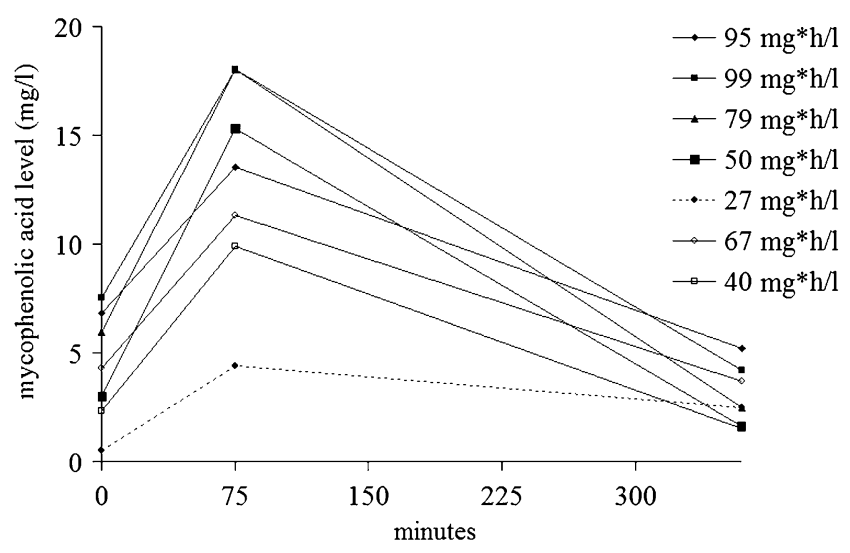

Fig. 4 Mycophenolic acid levels with area under the curve. Mycophenolic acid levels were measured using an immunoassay (filled symbols) or by high-performance liquid chromatographyultraviolet test (open symbols). Unbroken line no relapses, broken line three relapses in 6 months is successful but eventually leads to unwanted side effects, such as osteopenia, growth failure and cataract. A switch of medication is then necessary to prevent further relapses of nephrotic syndrome. The long-term treatment of children with CsA is effective but also has unfavourable side effects, of which hypertension and nephrotoxicity are the most important [6-11]. An alternative is welcome, and recent studies suggest a positive effect of MMF in children with nephrotic syndrome of various etiologies [12-21]. Here we report the first randomized controlled trial comparing the side effects and efficacy of MMF and CsA in children with frequently relapsing nephrotic syndrome.

The side-effect profile of MMF in our patients was more favourable than that of CsA. The mean estimated GFR in the MMF group increased with $6 \mathrm{ml} / \mathrm{min}$ per $1.73 \mathrm{~m}^{2}$ during 1 year of treatment compared to a decline of $14 \mathrm{ml} / \mathrm{min}$ per $1.73 \mathrm{~m}^{2}$ in the CsA group. This finding is in line with previous studies in which no nephrotoxicity of MMF was reported [28]. The reduction in the GFR in the CsA-treated patients may be related to the vasoconstrictive effects of CsA $[7,8]$. Although this haemodynamic effect can be reversible following the cessation of therapy, long-term treatment is often needed for remission maintenance in these children. In addition, it is well known that even after only 1 year of treatment with CsA, tubulointerstitial lesions can be found [29].

As expected, hypertrichosis and gingival hypertrophy were only seen in patients treated with CsA. Although diarrhea occurs in up to $43 \%$ of transplant recipients treated with MMF, we found only mild gastrointestinal symptoms, which is in agreement with recent studies on MMF in nephrotic children $[14,19]$. Surprisingly, our analysis of haematological parameters revealed that patients in the MMF group had a significantly higher haemoglobin level at 12 months than those in the CsA group. This finding is in contrast with studies reporting a negative effect of MMF on erythropoiesis in renal transplant recipients [30, 31]. However, none of our patients developed anemia, nor did any of the patients suffer from significant leucopenia or lymphopenia.

Our data suggest that CsA is more effective in preventing relapses than MMF, but the number of patients in our study is too small to draw definite conclusions on this endpoint. Despite the lack of previous randomized controlled trials proving the efficacy of MMF in nephrotic syndrome, pediatric nephrologists already feel that MMF is effective in these children. This made recruitment for our study difficult and explains the small number of children enrolled.

However, taking into account that all patients had a history of frequently relapsing nephrotic syndrome, the current relapse rate of $<1$ /patient per year even in the MMF group is a positive finding. One patient on MMF medication experienced treatment failure, with three relapses within 6 months, and needed alternative treatment. This patient had the lowest AUC of MPA. We hypothesize that 
dose adjustment in this patient might have improved the efficacy of the MMF drug therapy. An AUC was not available for the two patients with two relapses. One of these appeared to be non-compliant; in the second patient, the MMF was tapered to $50 \%$ of the original dose. As such, these patients may have had suboptimal MPA levels. Based on these anecdotal observations as well as on reports by others, we suggest that the issue of dose dependency should be further addressed in any prospective MMF trial in the future [13, 20, 23].

We used two methods for therapeutic drug monitoring: EMIT and HPLC. Westley et al. showed a good correlation between both methods $\left(r^{2}=0.851\right)$, with a small overestimation of MPA plasma concentration with the EMIT in the therapeutic range $($ EMIT $=0.973 \mathrm{HPLC}+0.55)[32]$. The pharmacokinetic profiles of MPA depict a lower level in six of seven patients after $6 \mathrm{~h}$ compared to predose level; this is due to the enterohepatic circulation of MPA glucuronide, which undergoes deglucuronidation and reabsorption as MPA [33, 34]. In renal transplant children, a secondary increase in MPA levels was observed, occurring 6-12 h after ingestion, which was compatible with enterohepatic recirculation $[34,35]$.

The preponderance of males in our study differs from the male:female ratio of 1.5 in children with first episode nephrotic syndrome, but it is in concert with a higher relapse frequency found in boys [1, 36, 37].

In conclusion, this study suggests a beneficial effect of MMF in children with frequently relapsing minimal change nephrotic syndrome. However, although MMF may not be as efficacious as CsA, the side-effect profile of MMF is much more benign. We postulate that there is a role for MMF in the treatment of frequently relapsing nephrotic syndrome in children; however, larger randomized controlled trials with therapeutic drug monitoring and individual dose adjustment are warranted.

Acknowledgements We are very grateful to the physicians who participated in the study and provided the follow up data: K.J.M van Hoeck, L.J.W.M. Pierik, J.G.J. Vande Walle and P. Vos. Roche provided the mycophenolate mofetil.

Open Access This article is distributed under the terms of the Creative Commons Attribution Noncommercial License which permits any noncommercial use, distribution, and reproduction in any medium, provided the original author(s) and source are credited.

\section{References}

1. International Study of Kidney Disease in Children (1978) The nephrotic syndrome in children, prediction of histopathology from clinical and laboratory characteristics at the time of diagnosis. Kidney Int 13:159-165
2. Tarshish P, Tobin JN, Bernstein J, Edelmann CM Jr (1997) Prognostic significance of the early course of minimal change nephrotic syndrome: report of the International Study of Kidney Disease in Children. J Am Soc Nephrol 8:769-776

3. Durkan A, Hodson EM, Willis NS, Craig JC (2005) Noncorticosteroid treatment for nephrotic syndrome in children. Cochrane Database Syst Rev: CD002290

4. International Study of Kidney Disease in Children (1974) Prospective controlled trial of cyclophosphamide therapy in children with nephrotic syndrome. Lancet 2:423-427

5. Latta K, von Schnakenburg C, Ehrich JHH (2001) A metaanalysis of cytotoxic treatment for frequently relapsing nephrotic syndrome in children. Pediatr Nephrol 16:271-282

6. Collaborative Study Group of Sandimmun in Nephrotic Syndrome (1991) Safety and tolerability of cyclosporin A (Sandimmun) in idiopathic nephrotic syndrome. Clin Nephrol 35:S48-S60

7. Hulton SA, Jadresic L, Shah V, Trompeter RS, Dillon MJ, Barratt TM (1994) Effect of cyclosporin A on glomerular filtration rate in children with minimal change nephrotic syndrome. Pediatr Nephrol 8:404-407

8. Tirelli AS, Paterlini G, Ghio L, Edefonti A, Assael BM, Bettinelli A, Cavanna G, Sereni F (1993) Renal effects of cyclosporin A in children treated for idiopatic nephrotic syndrome. Acta Paediatr 82:463-468

9. Gregory MJ, Smoyer WE, Sedman A, Kershaw DB, Valentini RP, Johnson K, Bunchman TE (1996) Long-term cyclosporine therapy for pediatric nephrotic syndrome: A clinical and histological analysis. J Am Soc Nephrol 7:543-549

10. Myers BD, Sibley R, Newton L, Tomlanovich SJ, Boshkos C, Stinson E, Luetscher JA, Whitney DJ, Krasny D, Coplon NS (1988) The long-term course of cyclosporine-associated chronic nephropathy. Kidney Int 33:590-600

11. Niaudet P, Habib R (1994) Cyclosporine in the treatment of idiopathic nephrosis. J Am Soc Nephrol 5:1049-1056

12. Bagga A, Hari P, Moudgil A, Jordan SC (2003) Mycophenolate mofetil and prednisolone therapy in children with steroiddependent nephrotic syndrome. Am J Kidney Dis 42:11141120

13. Mendizabal S, Zamora I, Berbel O, Sanahuja MJ, Fuentes J, Simon J (2005) Mycophenolate mofetil in steroid/cyclosporinedependent/resistant nephrotic syndrome. Pediatr Nephrol 20:914919

14. Ulinski T, Dubourg L, Said MH, Parchoux B, Ranchin B, Cochat P (2005) Switch from cyclosporine A to mycophenolate mofetil in nephrotic children. Pediatr Nephrol 20:482-485

15. Gellermann J, Querfeld U (2004) Frequently relapsing nephrotic syndrome: treatment with mycophenolate mofetil. Pediatr Nephrol 19:101-104

16. Barletta GM, Smoyer WE, Bunchman TE, Flynn JT, Kershaw DB (2003) Use of mycophenolate mofetil in steroid-dependent and resistant nephrotic syndrome. Pediatr Nephrol 18:833-837

17. Novak I, Frank R, Vento S, Vergara M, Gauthier B, Trachtman H (2005) Efficacy of mycophenolate mofetil in pediatric patients with steroid-dependent nephrotic syndrome. Pediatr Nephrol 20:12651268

18. Montane B, Abitbol C, Chandar J, Strauss J, Zilleruelo G (2003) Novel therapy of focal glomerulosclerosis with mycophenolate and angiotensin blockade. Pediatr Nephrol 18:772777

19. Bayazit AK, Noyan A, Cengiz N, Anarat A (2004) Mycophenolate mofetil in children with multidrug-resistant nephrotic syndrome. Clin Nephrol 61:25-29

20. Fujinaga S, Ohtomo $\mathrm{Y}$, Umino D, Takemoto M, Shimizu $T$, Yamashiro Y, Kaneko K (2007) A prospective study on the use of mycophenolate mofetil in children with cyclosporine-dependent nephrotic syndrome. Pediatr Nephrol 22:71-76 
21. Afzal K, Bagga A, Menon S, Hari P, Jordan SC (2007) Treatment with mycophenolate mofetil and prednisolone for steroid-dependent nephrotic syndrome. Pediatr Nephrol 22:2059-2065

22. Filler G (2006) Value of therapeutic drug monitoring of MMF therapy in pediatric transplantation. Pediatr Transplant 10:707-711

23. Filler G, Hansen M, LeBlanc C, Lepage N, Franke D, Mai I, Feber J (2003) Pharmacokinetics of mycophenolate mofetil for autoimmune disease in children. Pediatr Nephrol 18:445-449

24. National High Blood Pressure Education Program Working Group on High Blood Pressure in Children and Adolescents (2004) The fourth report on the diagnosis, evaluation, and treatment of high blood pressure in children and adolescents. Pediatrics 114:555-576

25. van Rossum LK, Mathot RA, Cransberg K, Zietse R, Vulto AG (2005) Estimation of the glomerular filtration rate in children: which algorithm should be used? Pediatr Nephrol 20:1769-1775

26. Schwartz GJ, Brion LP, Spitzer A (1987) The use of plasma creatinine concentration for estimating glomerular filtration in infants, children and adolescents. Pediatr Clin North Am 34:571-590

27. Schütz E, Armstrong VW, Shipkova M, Weber L, Niedmann PD, Lammersdorf T, Wiesel M, Mandelbaum A, Zimmerhackl LB, Mehls O, Tönshoff B, Oellerich M (1998) Limited sampling strategy for the determination of mycophenolic acid area under the curve in pediatric kidney recipients. Transplant Proc 30:1182-1184

28. Evans HM, McKiernan PJ, Kelly DA (2005) Mycophenolate mofetil for renal dysfunction after pediatric liver transplantation. Transplantation 79:1575-1580

29. Habib R, Niaudet P (1994) Comparison between pre- and posttreatment renal biopsies in children receiving ciclosporine for idiopatic nephrosis. Clin Neurol 42:141-146

30. van Besouw NM, van der Mast BJ, Smak Gregoor PJ, Hesse CJ, IJzermans JN, van Gelder T, Weimar W (1999) Effect of mycophenolate mofetil on erythropoiesis in stable renal transplant patients is correlated with mycophenolic acid trough levels. Nephrol Dial Transplant 14:2710-2713

31. Arbeiter K, Greenbaum L, Balzar E, Müller T, Hofmeister F, Bidmon B, Aufricht C (2000) Reproducible erythroid aplasia caused by mycophenolate mofetil. Pediatr Nephrol 14:195-197

32. Westley IS, Sallustio BC, Morris RG (2005) Validation of a highperformance liquid chromatography method for the measurement of mycophenolic acid and its glucuronide metabolites in plasma. Clin Biochem 38:824-829

33. Bullingham R, Monroe S, Nicholls A, Hale M (1996) Pharmacokinetics and bioavailability of mycophenolate mofetil in healthy subjects after single-dose oral and intravenous administration. J Clin Pharmacol 36:315-324

34. Jacqz-Aigrain E, Shaghaghi EK, Baudouin V, Popon M, Zhang D, Maisin A, Loirat C (2000) Pharmacokinetics and tolerance of mycophenolate mofetil in renal transplant children. Pediatr Nephrol 14:95-99

35. Weber LT, Lamersdorf T, Shipkova M, Niedmann PD, Wiesel M, Zimmerhackl LB, Staskewitz A, Schütz E, Mehls O, Oellerich M, Armstrong VW, Tönshoff B (1999) Area under the plasma concentration-time curve for total, but not for free, mycophenolic acid increases in the stable phase after renal transplantation: a longitudinal study in pediatric patients. German Study Group on Mycophenolate Mofetil Therapy in Pediatric Renal Transplant Recipients. Ther Drug Monit 21:498-506

36. Bakkali L, Rodrigues PR, Wijk JAEV (2007) Idiopatisch nefrotisch syndroom bij kinderen in Nederland in 2003-2006: resultaten van een nationale registratie. Tijdschr Kindergeneeskd S1:132

37. Lewis MA, Baildom EM, Davis N, Houston IB, Postlethwaite RJ (1989) Nephrotic syndrome: from toddlers to twenties. Lancet $1: 255-259$ 